\title{
Assessment and management of severely obese children and adolescents
}

'Sheffield Children's Hospital, Sheffield, UK

${ }^{2}$ Department of Endocrinology \& Diabetes, Lady Cilento Children's Hospital, Brisbane, Australia

Correspondence to Dr Neil Wright, Sheffield Children's Hospital, Western Bank, Sheffield S10 2TH, UK; N.P.Wright@sheffield.ac.uk

Received 25 November 2015 Revised 16 April 2016 Accepted 23 May 2016 Published Online First 16 June 2016

\author{
Neil Wright, ${ }^{1}$ Jerry Wales ${ }^{2}$
}

\section{ABSTRACT}

Approximately $3 \%$ of children and adolescents in the UK have severe obesity. The incidence of cardiovascular risk factors such as hypertension, hyperinsulinism and hyperlipidaemia approaches $20 \%$ in such individuals. Lifestyle intervention programmes and pharmacotherapy are effective in some individuals, but the relapse rate is high. In exceptional cases, bariatric surgery is effective. This review outlines the scale of the problem, highlights those at risk and discusses referral, current services, appropriate screening and therapeutic interventions.

Overweight and obesity represent a rapidly growing threat to both physical and psychological health of children. The recent 2014/2015 data from the UK National Schools Measurement Programme suggest that at school entry (age 5 years), $21.9 \%$ of children are overweight (body mass index (BMI) $>85$ th centile) and $9.1 \%$ of children are obese (BMI $>95$ th centile). ${ }^{1}$ By the age of 11 years, $33.2 \%$ of children are overweight and $19.1 \%$ obese. ${ }^{1}$ More significantly, approximately $2.9 \%$ of girls and $3.9 \%$ of boys aged 11 years have severe obesity (defined by BMI $>99$ th centile). ${ }^{2}$ One of the key concerns about childhood obesity is that it tracks into adult life. ${ }^{3}$ Children who are obese tend to become obese adults. The greater the severity of childhood obesity, the greater the degree of adult obesity. ${ }^{3}$ The situation is compounded by the fact that up to $75 \%$ of parents do not recognise that their child is overweight and when they do recognise it up to $40 \%$ do not appreciate the potential health risks. ${ }^{4}$

Given the high proportion of children and adolescents who are obese, how should clinicians assess obesity and in whom should we consider further investigation? BMI is recommended as the most appropriate measure of overweight and obesity. It has limitations and it is not a direct measure of adiposity. ${ }^{5}$ It can overstate the degree of overweight, particularly in tall lean children. However, alternatives such as waist:hip ratio, dual energy $\mathrm{x}$-ray absorptiometry (DEXA) assessment of body fat and skin fold thickness are more complex to use. In routine practice, BMI remains the most reliable metric. ${ }^{5}$ In children, BMI varies significantly with age, so unlike adults a single definition cannot be used (in adults, BMI $>25 \mathrm{~kg} / \mathrm{m}^{2}$ is defined as overweight and BMI $>30 \mathrm{~kg} / \mathrm{m}^{2}$ as obese -an adult BMI of 30-34.9 is termed as class 1 obesity, a BMI of 35.0-39.9 as class 2 obesity and an adult BMI of $>40$ as class 3 obesity-formerly morbid obesity). It is important, therefore, to make use of BMI centile charts in paediatrics (see figure 1). ${ }^{6}$

It is also important to appreciate the different definitions of overweight and obesity used for epidemiological monitoring purposes and for clinical assessment. Within the National Child Measurement Programme, a BMI $>85$ th centile is defined as overweight and $>95$ th centile obese. ${ }^{1}$ In clinical practice, cut-offs suggested by the Scottish Intercollegiate Guideline Network (SIGN) guidance, based on the UK 1990 Growth Cohort, are that a BMI >91st centile should be considered overweight, $>98$ th centile obese and $>99.6$ th centile severe obesity. The SIGN guidance also suggests further thresholds based on SD scores (SDSs) of $>3.5$ SD for 'very severe' obesity and $>4.0$ SD for 'extreme obesity'. A childhood BMI SDS of $>3.5$ is equivalent to an adult BMI of 40 -class 3 obesity-morbid obesity. ${ }^{8}$ Differing definitions are used and the most widely used definition of severe paediatric obesity in the literature is BMI $>99$ th centile, which is equivalent to an adult BMI $>30 \mathrm{~kg} / \mathrm{m}^{2}$ (class 1 obesity). ${ }^{2}$ This definition is in line with the International Obesity Task Force definitions of overweight, which approximate to the 91st centile for overweight and 99th centile for obesity. ${ }^{9}$

There is no clear threshold at which children are at increased risk of comorbidities. Even children with modest degrees of overweight and obesity have an adverse metabolic cardiovascular risk profile. The Bogalusa Heart Study in the USA demonstrated that in children aged 5-10 years of those overweight (BMI >85th centile), 7\% had systolic hypertension; in obese children, $12 \%$ had high blood pressure and in severely obese children, 22\% had raised blood pressure. ${ }^{10}$ Similar adverse risk profiles were seen for raised cholesterol, triglycerides and elevated fasting insulin levels in children aged 5-10 years and those aged $11-17$ years. ${ }^{10}$ Obese children were 7 times more likely to have raised triglycerides and 12 times more likely to have raised fasting insulin levels. ${ }^{10}$ In another North American study, impaired glucose tolerance was detected in $25 \%$ of obese children (4-10 years of age) and $21 \%$ of obese adolescents (11-18 years of age). ${ }^{11}$ Previously undetected type 2 diabetes was present in $4 \%$ of the adolescents. ${ }^{11}$ In all studies, increasing obesity was associated with a sharp increase in the incidence of hypertension, hyperinsulinism and hyperlipidaemia. Similarly, obstructive sleep apnoea is reported to occur in up to $60 \%$ of patients with extreme obesity (BMI +4.0 SDS) and in approximately $10 \%$ of children with severe obesity. ${ }^{12}$ A meta-analysis of over 30 studies demonstrated non-alcoholic fatty liver disease (alanine transaminase (ALT) twice the upper limit of normal) in up to $34 \%$ of children with severe obesity. ${ }^{13}$

What is often underestimated is the impact on psychological health and general well-being of childhood obesity. In a cross-sectional study, 34\% of obese girls had low self-esteem compared with $8 \%$ of the control population. ${ }^{14}$ Obese adolescents 


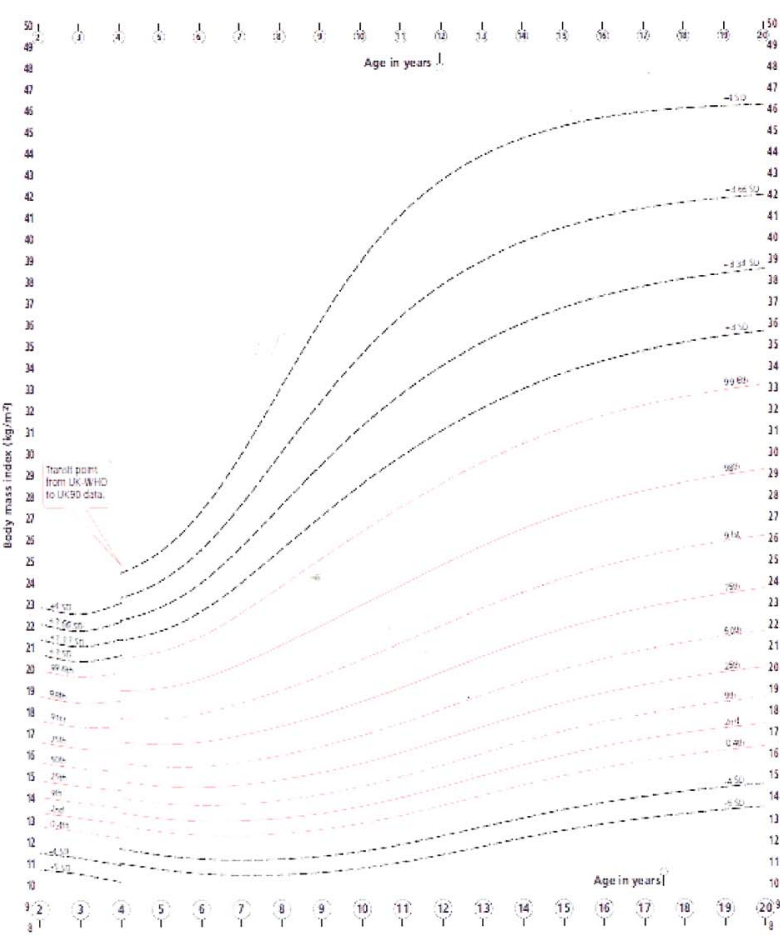

Reproduced with permission from Royal College Paediatrics and Child Health (RCPCH)

http://www.rcpch.ac.uk/childhealth/research-projects/uk-who-growth-charts

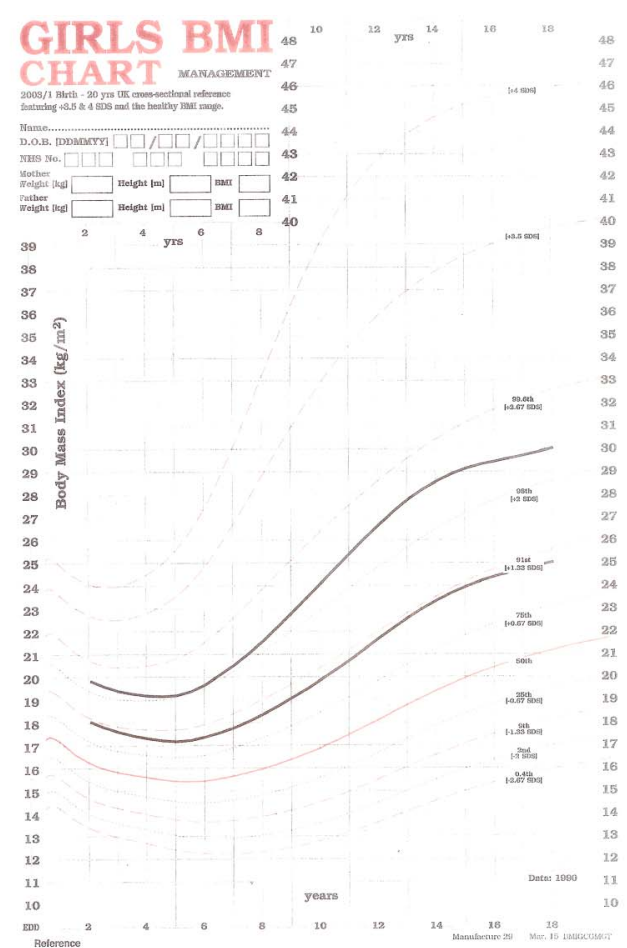

Reproduced with permission from Child Growth Foundation http://www.childgrowthfoundation.org

Figure 1 Examples of the two most widely used body mass index (BMI) centile charts in the UK based on the UK 1990 Growth Cohort and incorporating SD scores to illustrate very severe and extreme childhood obesity together with the International Obesity Task force cut-offs. ${ }^{6}{ }^{9}$

have lower levels of academic educational attainment and progression into higher education, are less likely to form stable relationships and are significantly more likely to live in poverty in later life. $^{15}$

Even at modest levels of obesity, potential long-term risk factors are evident in both prepubertal and postpubertal children. As the degree of obesity increases, the risk of weight-related health problems increases sharply. So, who needs further assessment? The consensus statement from the Obesity Services for Children and Adolescents (OSCA) network suggested that any child with a BMI >98th centile should be assessed-in primary care initially and opportunistically in secondary care. ${ }^{8}$ It suggested formal referral to secondary care for those with identified comorbidities and for any child with a BMI SDS > 3.5-'very severe obesity'.

Services for the management and treatment of overweight and obesity in children are organised in line with a classical commissioning pyramid (see figure 2). Tier 1 consists of public health measures, simple ad hoc interventions and opportunistic advice to families. Many families fail to identify that their child is overweight. Studies have suggested that professional identification of overweight does prompt some families to seek support without there being any evidence to suggest it does harm. ${ }^{16}$ Clinicians should therefore where possible seek opportunistically to discuss a child's weight.

At all levels of obesity, lifestyle modifications and lifestyle interventions are fundamental to management. Where a child is identified as having a problem, a referral to a local Tier 2 community weight management programme should be considered. There is wide variation in the provision of interventions in the UK. Some are commissioned from providers such as MEND, More Life and Alive \& Kicking who provide programmes in a

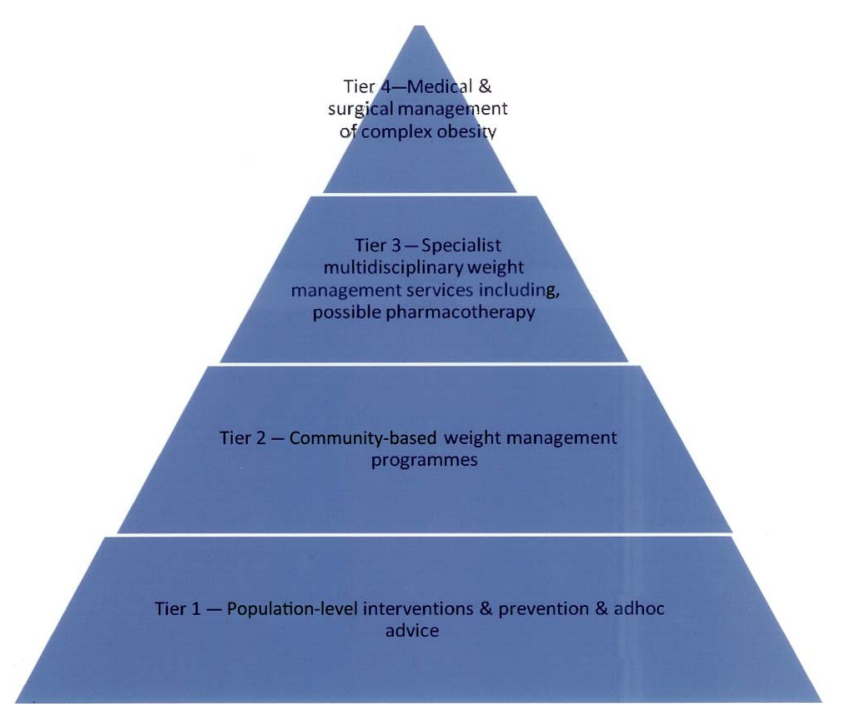

Figure 2 Commissioning pyramid for the organisation of weight management services for children.

number of different localities. Others are locally developed. Programmes typically comprise of group sessions, frequently at a local sports centre, with individuals attending once or twice a week for 10-12 week programme. A large number of studies of lifestyle interventions in children have been reported. ${ }^{17}$ Studies have varied in quality, nature of the intervention, clinical setting and the degree of obesity addressed.

A number of high-quality systematic reviews and meta-analyses of the evidence have been conducted-principally, the evidence summary for the National Institute for Health and 
Care Excellence (NICE) Clinical Guideline CG43, ${ }^{5}$ the Cochrane review 'Interventions for treating childhood obesity' published in $2010^{17}$ and the systematic review commissioned for the US Preventative Services Task Force (USPSTF) published in $2008 .^{18}$ The conclusions of these evidence reviews were similar:

- There were no data to recommend any one particular lifestyle intervention or treatment programme over another.

- Combined behavioural and lifestyle interventions (focusing on diet, activity levels and behavioural management) were most effective though the relapse rate was high.

- In all age groups, but particularly in younger children, interventions focused on families and parents as opposed to young people were most effective.

- Behavioural interventions of medium to high intensity conducted in specialist facilities were most effective compared with low-intensity interventions in primary care.

- In adolescents, pharmacological treatment as an adjunct to lifestyle intervention alone was more effective, but again with a high relapse rate when treatment is discontinued.

The meta-analysis commissioned by USPSTF suggested a 1.9$3.3 \mathrm{~kg} / \mathrm{m}^{2}$ difference in $\mathrm{BMI}^{18}$ and the Cochrane review suggested a reduction in BMI of $3.0 \mathrm{~kg} / \mathrm{m}^{2} .{ }^{17}$

NICE in its initial guideline CG43 in 2006 and partial update CG189 published in 2014 makes a number of specific recommendations regarding the emphasis and composition of lifestyle intervention programmes, which should be reflected in advice clinicians offer (see figure 3). ${ }^{519}$ The key recommendations are that the emphasis should not be on diet alone but on a combination of diet and increasing physical activity. At least 60 min of moderate activity a day is recommended with a reduction in the time spent on sedentary pastimes. ${ }^{5} 19$ Diet should include calorie reduction not simply advice about healthy eating. In adolescents, recommendations suggest aiming for a weight loss of $0.5-1.0 \mathrm{~kg} /$ month. ${ }^{5}{ }^{19}$ In younger children, who are growing more rapidly weight maintenance may be an appropriate goal to aim for rather than weight loss. ${ }^{19}$

Few community weight management programmes address the identification of comorbidities, so it is important that referring clinicians consider comorbidities such as impaired glucose tolerance, dyslipidaemia, blood pressure and snoring, which might be indicative of obstructive sleep apnoea (see table 1).

Parental weight is a key determinant of weight in childhood. If one parent is overweight, a child is 3 times more likely to be overweight and if both parents are overweight, a child is 10 times more likely to be overweight. This often raises the question as to what extent overweight in children is environmental and to what extent it may be genetic. Twin studies have demonstrated that genetic factors account for between $40 \%$ and $70 \%$
Figure 3 National Institute for Health and Care Excellence (NICE) recommendations regarding Diet, Exercise, Pharmacotherapy and Bariatric Surgery for childhood obesity. ${ }^{5} 19$

\section{Diet \\ - A dietary approach alone is not recommended. It is essential that any dietary recommendations are part of a multicomponent intervention. [2006] \\ - For overweight and obese children and young people, total energy intake should be below their energy expenditure. Changes should be sustainable.}

\section{Activity}

- Encourage children and young people to increase their level of physical activity, even if they do not lose weight as a result, because of the other health benefits exercise can bring

- Encourage children to do at least 60 minutes of moderate or greater intensity physical activity each day. The activity can be in 1 session or several sessions lasting 10 minutes or more. [2006]

- Be aware that children who are already overweight may need to do more than 60 minutes activity. [2006, amended 2014]

- Encourage children to reduce inactive behaviours, such as sitting and watching television, using a computer or playing video games. [2006]

- Give children the opportunity and support to do more exercise in their daily lives (for example, walking, cycling, using the stairs and active play)

- Make the choice of activity with the child, and ensure it is appropriate to the child's ability and confidence. [2006]

\section{Pharmacological Intervention}

- Drug treatment is not generally recommended for children younger than12 years. [2006]

- In children younger than 12 years, drug treatment may be used only in exceptional circumstances, if severe comorbidities are present. Prescribing should be started and monitored only in specialist paediatric settings. [2006, amended 2014]

- In children aged 12 years and older, treatment with orlistatis recommended only if physical comorbidities (egorthopaedic problems or sleep apnoea) or severe psychological comorbidities are present. Treatment should be started in a specialist paediatric setting, by multidisciplinary teams with experience of prescribing in this age group. [2006, amended 2014]

- Do not give orlistat to children for obesity unless prescribed by a multidisciplinary team with expertise in obesity. Drug treatment may be continued in primary care for example with a shared care protocol

- If orlistatis prescribed for children, a 6-12-month trial is recommended, with regular review

\section{Bariatric Surgery}

- Surgical intervention is not generally recommended in children or young people. [2006]

- Obesity surgery may be considered for young people in exceptional circumstances if they have achieved or nearly achieved physiological maturity. [2006] 
of the difference in BMI within the population. ${ }^{23}$ However, in 'common' obesity, at least 32 different genetic loci have been associated with BMI. The polymorphisms at these loci cumulatively explain only $1.5 \%$ of the variation in BMI within the population. $^{24}$ This would account for $7.0-8.0 \mathrm{~kg}$ difference in adult weight where an individual to have polymorphisms at all 32 loci. The most common gene polymorphism, FTO, accounts for only $0.34 \%$ of the population variability in BMI-1.5$2.0 \mathrm{~kg}$ in weight. ${ }^{24}$ In contrast, in children with severe obesity (BMI > +3.0 SDS) and in particular those with early-onset severe obesity (within the first 5 years of life-typically within the first year of life), up to $10 \%$ of individuals have been identified as having a monogenic cause of obesity. ${ }^{20}$ In children with very severe early-onset obesity, referral to a tertiary specialist obesity service for consideration of genetic causes, particularly in children with learning difficulties or those with clinical hyerphagia and lack of satiety may be appropriate (see figure 4). ${ }^{8} 25$ In the majority however, while it is important to recognise that there may be a familial predisposition, one should explain to families it is not currently recommended that such polymorphisms be investigated by routine genetic testing as the contribution to overweight is small. ${ }^{25}$ The emphasis should remain on lifestyle modification.

In children with early-onset severe obesity, those with very severe obesity, those who have failed to lose weight with Tier 2 programmes, those who have relapsed and those with significant comorbidities, NICE recommends referral to Tier 3 specialist obesity services. ${ }^{19}$ Figure 5 illustrates a possible pathway via which children may be managed, initially in Tier 2 and indicates points at which Tier 3 referral may be appropriate. Unfortunately, even for adults, there are few commissioned Tier 3 services and lifestyle interventions are not well differentiated from Tier 2 services (many are repeats of Tier 2 services). ${ }^{26}$ For children, service provision is even more fragmented. There are few, if any, commissioned Tier 3 multidisciplinary services that meet the NICE specification.

In children and adolescents unable to manage their weight with community interventions and who have weight-related
Table 1 Investigations to consider for screening of weight-related comorbidities

\begin{tabular}{|c|c|}
\hline $\begin{array}{l}\text { Enquiry/ } \\
\text { investigation }\end{array}$ & Rationale \\
\hline $\begin{array}{l}\text { Family history } \\
\text { and age-onset } \\
\text { obesity }\end{array}$ & $\begin{array}{l}\text { Children with a very strong parental history of obesity and } \\
\text { early-onset obesity ( }<5 \text { years) are more likely to have a } \\
\text { monogenic cause for their obesity. }{ }^{20}\end{array}$ \\
\hline $\begin{array}{l}\text { Assess growth } \\
\text { and puberty }\end{array}$ & $\begin{array}{l}\text { Children with endocrinopathy tend to be short and } \\
\text { overweight, while those with nutritional obesity tend to be } \\
\text { tall and overweight (compared with mid-parental height). } \\
\text { Individuals with endocrinopathies such as Cushing's show } \\
\text { arrested growth. }\end{array}$ \\
\hline Blood pressure & $\begin{array}{l}\text { Up to } 20 \% \text { children with severe obesity may have } \\
\text { hypertension. }\end{array}$ \\
\hline $\begin{array}{l}\text { Liver function } \\
\text { tests }\end{array}$ & $\begin{array}{l}\text { Non-alcoholic fatty liver disease (NAFLD) as a consequence of } \\
\text { obesity is common. An ALT >twice the upper limit of normal } \\
\text { range suggests fatty liver. }{ }^{13}\end{array}$ \\
\hline Lipids & $\begin{array}{l}\text { Risk of raised cholesterol and triglycerides is increased } \\
\text { sevenfold in severe obesity. }\end{array}$ \\
\hline \multirow[t]{3}{*}{$\begin{array}{l}\text { Fasting insulin } \\
\text { and fasting } \\
\text { glucose }\end{array}$} & $\begin{array}{l}\text { If the fasting insulin and glucose are raised with a high } \\
\text { HOMA score }(>4.5) \text {, consider an oral glucose tolerance test. } \\
\text { HOMA is a measure of insulin resistance }\end{array}$ \\
\hline & \multirow{2}{*}{$\mathrm{HOMA}=\frac{\text { fasting insulin }(\mathrm{mU} / \mathrm{L}) \times \text { fasting glucose }(\mathrm{mmol} / \mathrm{L})}{22.5}$} \\
\hline & \\
\hline Thyroid function & $\begin{array}{l}\text { Exclude hypothyroidism though modest rises in TSH are } \\
\text { common in obese children. It is not recommended that mild } \\
\text { subclinical hypothyroidism (TSH }<10.0 \text { ) is treated. }{ }^{21}\end{array}$ \\
\hline $\begin{array}{l}\text { Consider } \\
\text { obstructive } \\
\text { sleep apnoea }\end{array}$ & $\begin{array}{l}\text { Enquiring about snoring and consideration of a screening } \\
\text { questionnaire may assist in identifying those who may need } \\
\text { further investigation for obstructive sleep apnoea. }{ }^{22}\end{array}$ \\
\hline $\begin{array}{l}\text { Enquire about } \\
\text { menstrual } \\
\text { irregularities } \\
\text { and hirsutism }\end{array}$ & $\begin{array}{l}\text { In overweight/obese girls, ovarian hyperandrogenism is } \\
\text { common and menstrual irregularities and hirsutism frequently } \\
\text { occur. Investigation of follicle stimulating hormone (FSH), } \\
\text { lutenising hormone (LH), sex hormone binding globulin } \\
\text { (SHBG) and testosterone may be indicated. }\end{array}$ \\
\hline $\begin{array}{l}\text { Consider } \\
\text { screening for } \\
\text { vitamin D } \\
\text { deficiency }\end{array}$ & $\begin{array}{l}\text { Vitamin D deficiency is common in overweight/obese children } \\
\text { as a consequence of vitamin D deposition in fatty tissues and } \\
\text { diet. }\end{array}$ \\
\hline
\end{tabular}

Figure 4 Prioritisation for screening for monogenic obesity in children with early-onset severe obesity and hyperphagia-Reproduced with permission from Choquet \& MeyreGenome Medicine 2010 published by BioMed Central. ${ }^{20}$

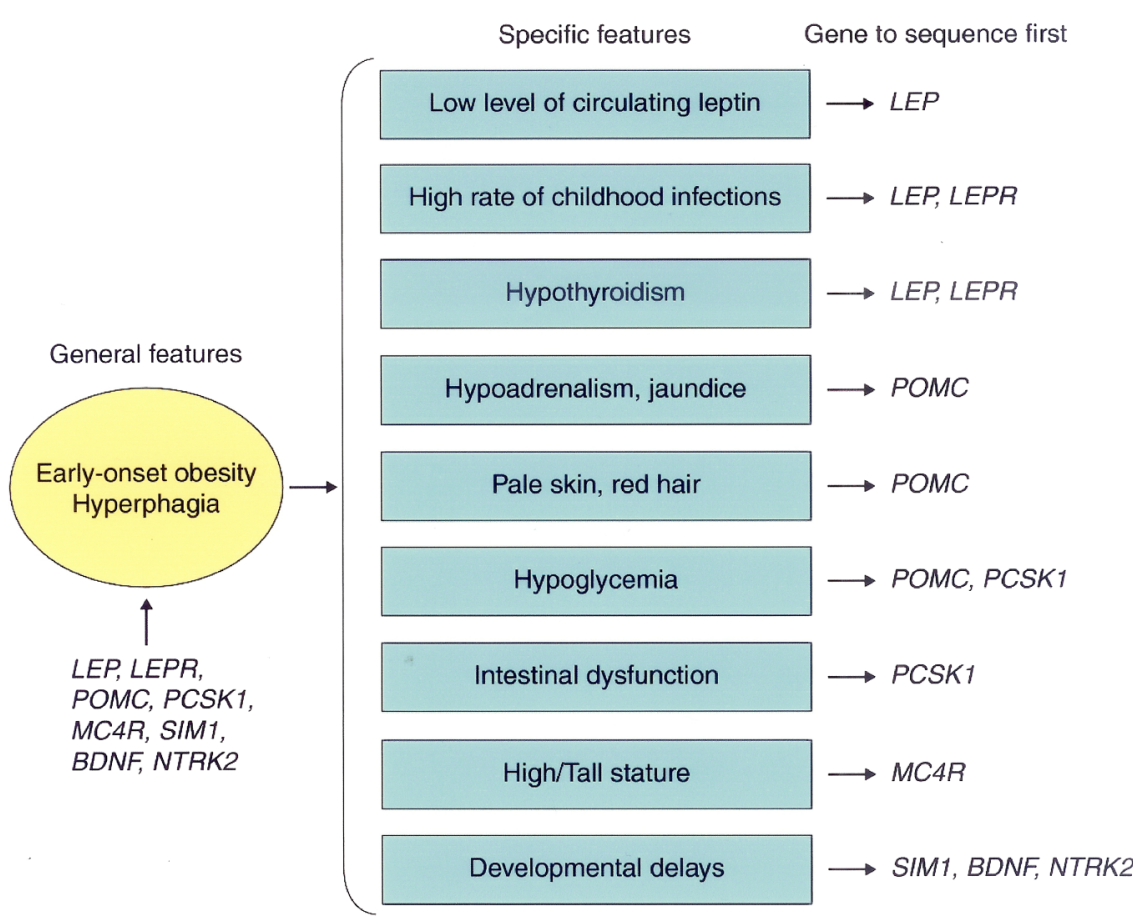


comorbidities, the question as to whether pharmacological intervention is appropriate arises. NICE guidance does not recommend drug therapy except in specific circumstances. ${ }^{5} 19$

- In children < 12 years of age, "drug treatment may be used only in exceptional circumstances, if severe comorbidities are present. Prescribing should be started and monitored only in specialist paediatric settings."

- In children >12 years of age- "treatment with orlistat is recommended only if physical comorbidities (such as orthopaedic problems or sleep apnoea) or severe psychological problems are present. Treatment should be started in a specialist paediatric setting by multidisciplinary teams with experience of prescribing in this age group."

The Scottish SIGN guidelines suggest pharmacological intervention may be appropriate with severe obesity, BMI >99.6 centile when there are comorbidities or with very severe $(>3.5$ SDS) or extreme obesity (>4.0 SDS) across the age spectrum, including younger children. ${ }^{7}$ Both recommend that treatment under the umbrella of a 'specialist clinic'.

Although therapeutic options are limited, the prescribing of medication for children and adolescents has risen 15-fold over the last decade. ${ }^{27}$ Of the three drugs licensed and marketed for weight loss over recent years, only Orlistat remains available. Rimonabant which blocked centrally located cannabinoid receptors decreasing food intake and sibutramine a centrally acting serotonin reuptake inhibitor have both been withdrawn due to side effects. Orlistat is licensed by the Federal Drug Administration for use in individuals over 12 years. Orlistat, a pancreatic lipase inhibitor, reduces fat absorption from the diet by about $30 \% .^{28}$ This results in a reduction in calorie intake of approximately 200 calories per day. NICE recommends that where Orlistat is considered, a 6-12-month trial is undertaken, and a multivitamin supplementation is given as it reduces absorption of fat-soluble vitamins. ${ }^{19}$ Several studies have examined the efficacy of Orlistat in adolescent populations. One systematic review suggested that Orlistat together with dietary and exercise counselling led to an average weight loss of $2.3 \mathrm{~kg}$ over 12 months with a reduction in BMI of $0.83 \mathrm{~kg} / \mathrm{m}^{2}{ }^{29}$ A separate meta-analysis included different studies and suggested a reduction in BMI of $1.67 \mathrm{~kg} / \mathrm{m}^{2}$ with an absolute weight loss of $6 \mathrm{~kg} .{ }^{30}$ Only one very small study has looked at Orlistat in prepubertal children $<12$ years and demonstrated a weight loss of approximately $4.0 \mathrm{~kg}$ over a 3 -month period. ${ }^{31}$ While Orlistat does appear to support modest weight loss of between 2.5 and $6.0 \mathrm{~kg}$ in both prepubertal and adolescent children, it is not well tolerated. Gastrointestinal side effects have been reported in up to $50 \%$ of participants and dropout rates from studies range from $6 \%$ to $33 \% .{ }^{30} \mathrm{UK}$ prescribing data suggest that $45 \%$ of individuals prescribed Orlistat take it for less than a month before discontinuing treatment. ${ }^{27}$

There is some evidence that metformin, a biguanide oral hypoglycaemic agent, is efficacious in promoting weight loss. A meta-analysis of pooled data from five studies suggested a reduction in BMI of $1.4 \mathrm{~kg} / \mathrm{m}^{2}$ compared with placebo. ${ }^{29}$ Participants reported gastrointestinal side effects in $20-30 \%$ of cases, but dropout rates were relatively low at $<12 \% .{ }^{29}$ Metformin

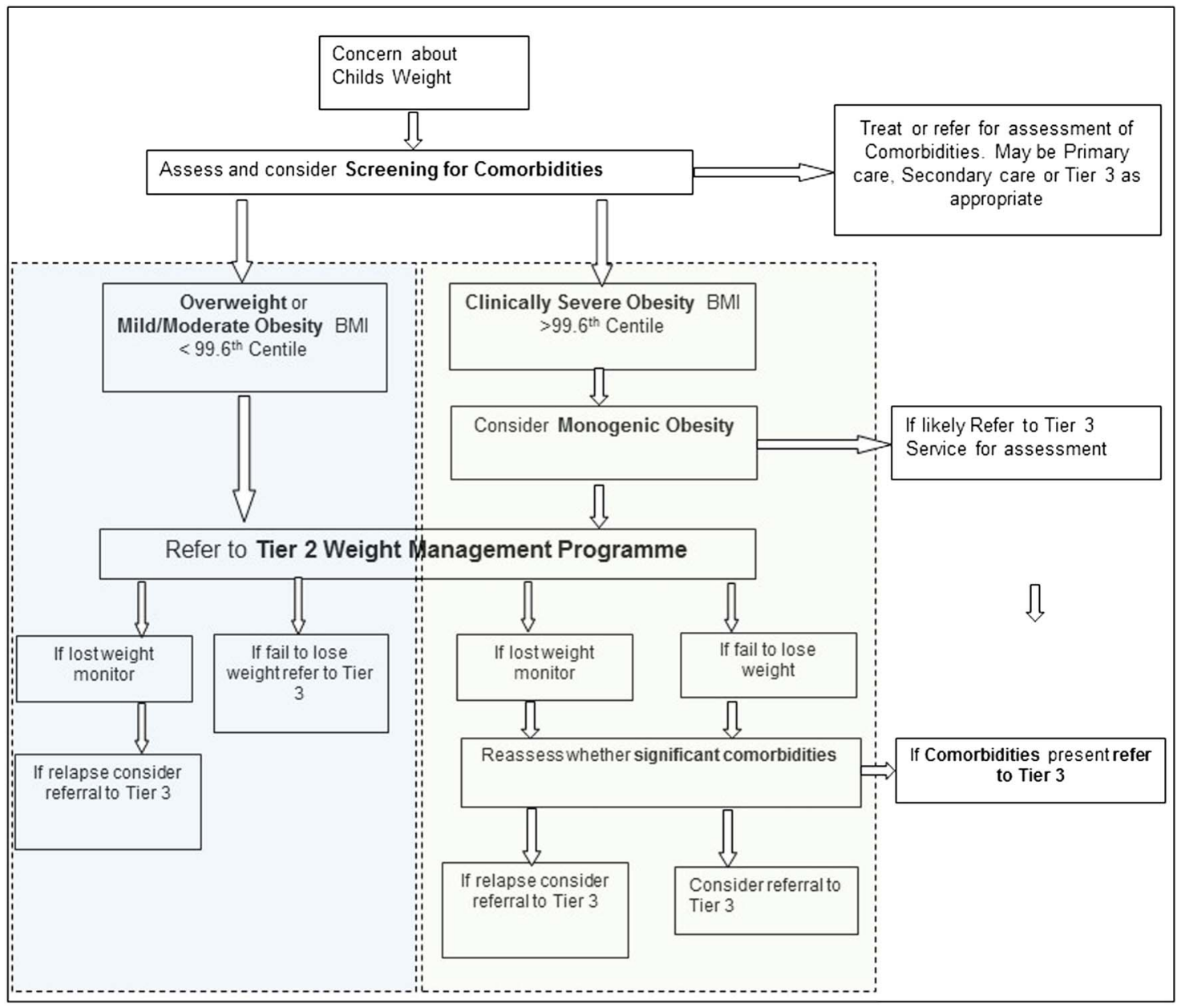

Figure 5 A possible pathway by which to consider the investigation and management of children with obesity. 
also produces modest reductions in cholesterol and insulin resistance. In younger children less than 12 years, weight loss of approximately $3.4 \mathrm{~kg}$ has been reported (reduction in BMI of $\left.1.09 \mathrm{~kg} / \mathrm{m}^{2}\right) .{ }^{32}$ Long-term randomised controlled trials evaluating the role of metformin for weight loss alone are required but small relatively short clinical trials, typically of 6 months, do provide some preliminary evidence that metformin may be beneficial in promoting weight loss and modifying cardiovascular risk factors. It may be appropriate in those with impaired glucose tolerance or high fasting insulin or Homeostatic Model Assessment (HOMA) score >4.5. ${ }^{8}$ However, studies have shown that weight loss is more effective than metformin in improving hyperinsulinism. ${ }^{33}$

Most comorbidities improve with weight loss and this should be the primary objective. How much weight an individual needs to lose to benefit in health terms is difficult to define but $5-7 \%$ would likely have significant benefit. In adults, weight loss of $7 \%$ substantially reduced the risk of developing type 2 diabetes. $^{33}$ In orthopaedic conditions like knee problems, 5\% weight loss conferred significant benefit. ${ }^{34}$ Where individuals fail to lose weight, comorbidities may need specific treatment.

A number of drugs are currently under investigation regarding their potential to promote weight loss. The glucagon-like peptide agonists Liraglutide and Exenatide have shown modest dose-dependent improvements in body weight averaging -1.6 to $-2.8 \mathrm{~kg} .{ }^{35}$ Topiramate, an anticonvulsant GABA agonist, has also been noted to suppress appetite and promote weight loss. ${ }^{36}$ None of these drugs, trialled in adults, has yet received a licence to treat obesity.

For those with very severe/extremely severe obesity and established comorbidities, bariatric surgery for adolescents is undoubtedly efficacious, but its use remains controversial. Were they to be over 18 years, such individuals would meet the NICE guidance criteria for bariatric surgery (BMI $>40$ and $\mathrm{BMI}>35$ with comorbidities). ${ }^{19}$ Bariatric surgery, for example, reverses type 2 diabetes in adolescents. NICE makes provision within its guidance for consideration of obesity surgery in adolescents in exceptional circumstances (see figure 3). NHS England is currently examining the commissioning of Tier 4 bariatric services for adolescents but while there are currently no formally commissioned services, several UK centres offer surgery in exceptional circumstances. A meta-analysis of 23 studies (incorporating data from 637 patients) demonstrated a reduction in BMI at 1 year of $13.5 \mathrm{~kg} / \mathrm{m}^{2} .{ }^{37}$ Our own experience demonstrated an average weight loss of $67 \mathrm{~kg}$ with a mean reduction in weight from 177 to $123 \mathrm{~kg}$ and BMI from 64.7 to $46.3 \mathrm{~kg} / \mathrm{m}^{2}$ 2 years postprocedure. ${ }^{38}$ However, such procedures remain a last resort only when other options have been unsuccessful.

Childhood obesity is a significant problem in the UK. Many parents do not fully appreciate that their children are overweight and it is important that clinicians identify children who are overweight and obese. In children with severe obesity ( $>99$ th centile), weight frequently tracks from childhood into adult life and the incidence of longer term cardiovascular and metabolic risk factors is high. It is important that these are identified that children and their families are encouraged to participate in lifestyle intervention programmes. Where these are unsuccessful or children have serious comorbidities, they should be signposted to specialist weight management services for further investigation and management.

Correction notice This paper has been amended since it was published Online First. The copyright notice for figure 1, second panel has been changed.

Contributors NW drafted the manuscript and JW and NW both expanded and revised the initial draft.
Competing interests None declared.

Provenance and peer review Commissioned; externally peer reviewed.

\section{REFERENCES}

1 Health and Social Care Information Centre. Statistics on Obesity, National Child Measurement programme-England 2014-2015. Published November 2015. www.hscic.gov.uk/ncmp.

2 Ells LJ, Hancock C, Copley VR, et al. Prevalence of severe childhood obesity in England: 2006-2013. Arch Dis Child 2015;100:631-6.

3 Dietz WH. Health consequences of obesity in youth: childhood predictors of adult disease. Pediatrics 1998;101:518-25.

4 Park $\mathrm{MH}$, Falconer $\mathrm{CL}$, Saxena $\mathrm{S}$, et al. Perceptions of health risk among parents of overweight children: a cross-sectional study within a cohort. Prev Med 2013;57:55-9.

5 National Institute for Clinical Excellence (NICE). Obesity: the prevention, identification, assessment and management of overweight and obesity in adults and children-Clinical Guideline 43. 2006. www.nice.org.uk/guidance/Cg43

6 Cole TJ, Freeman JV, Preece MA. Body mass index reference curves for the UK, 1990. Arch Dis Child 1995:73:25-9.

7 Scottish Intercollegiate Guidelines Network. Management of Obesity_SIGN Guideline 115. 2010. www.sign.ac.uk/pdf/sign115.pdf

8 Viner RM, White B, Barrett T, et al. Assessment of childhood obesity in secondary care: OSCA consensus statement. Arch Dis Child Educ Pract Ed 2012;97:98-105.

9 Cole TJ, Bellizzi MC, Flegal KM, et al. Establishing a standard definition for child overweight and obesity worldwide: international survey. BMJ 2000:320:1240-3.

10 Freedman DS, Dietz WH, Srinivasan SR, et al. The relation of overweight to cardiovascular risk factors among children and adolescents: the Bogalusa Heart Study. Pediatrics 1999;103:1175-82.

11 Sinha R, Fisch G, Teague B, et al. Prevalence of impaired glucose tolerance among children and adolescents with marked obesity. N Engl J Med 2002;346:802-10.

12 Arens R, Muzumdar H. Childhood obesity and obstructive sleep apnea syndrome. J App/ Physiol 2010;108:436-44.

13 Anderson $\mathrm{EL}$, Howe LD, Jones $\mathrm{HE}$, et al. The prevalence of non-alcoholic fatty liver disease in children and adolescents: a systematic review and meta-analysis. PLOS ONE 2015;10:e0140908.

14 Strauss RS. Childhood obesity and self-esteem. Pediatrics 2000;105:e15.

15 Gortmaker SL, Must A, Perrin JM, et al. Social and economic consequences of overweight in adolescence and young adulthood. $N$ Engl J Med 1993:329:1008-12

16 Falconer $\mathrm{CL}$, Park $\mathrm{MH}$, Croker $\mathrm{H}$, et al. The benefits and harms of providing parents with weight feedback as part of The National child measurement programme: a prospective cohort study. BMC Public Health 2014;14:549.

17 Oude LH, Baur L, Jansen $\mathrm{H}$, et al. Interventions for treating obesity in children. Cochrane Database Syst Rev 2009;(1):CD001872.

18 Whitlock E, O'Connor E, Williams S, et al. Effectiveness of weight management programs in children and adolescents. Evid Rep Technol Assess (Full Rep) 2008:170:1-308.

19 National Institute for Health and Care Excellence (UK). Obesity: Identification, Assessment and Management of Overweight and Obesity in Children, Young People and Adults: Partial Update of CG43. NICE Clinical Guidelines No. 189. 2014. www.nice.org.uk/guidance/Cg189

20 Choquet H, Meyre D. Genomic insights into early-onset obesity. Genome Med 2010;2:36.

21 Niranjan U, Wright NP. Should we treat subclinical hypothyroidism in obese children? BMJ. 2016;352:i941.

22 Kadmon G, Chung SA, Shapiro CM. I'M SLEEPY: a short pediatric sleep apnea questionnaire. Int J Pediatr Otorhinolaryngol 2014;78:2116-20.

23 Phan-Hug F, Beckmann JS, Jacquemont S. Genetic testing in patients with obesity Best Pract Res Clin Endocrinol Metab 2012;26:133-43.

24 Speliotes EK, Willer CJ, Berndt SI, et al. Association analyses of 249,796 individuals reveal 18 new loci associated with body mass index. Nat Genet 2010;42:937-48.

25 Aston LM, Kroese M. Genomics of obesity - the application of Public Health Genomics to the prevention and Management of Obesity in the UK. PHG Foundation, 2013

26 Read S, Logue J. Variations in weight management services in Scotland: a national survey of weight management provision. J Public Health (Oxf) 2015. http:// jpubhealth.oxfordjournals.org/content/early/2015/09/19/pubmed.fdv132.full.pdf+html

27 Viner RM, Hsia Y, Neubert A, et al. Rise in antiobesity drug prescribing for children and adolescents in the UK: a population-based study. Br J Clin Pharmacol 2009:68:844-51.

28 Guerciolini R. Mode of action of orlistat. Int J Obes Relat Metab Disord 1997;21 (Suppl 3):S12-23.

29 Viner RM, Hsia Y, Tomsic T, et al. Efficacy and safety of anti-obesity drugs in children and adolescents: systematic review and meta-analysis. Obes Rev 2010;11:593-602.

30 Czernichow S, Lee CM, Barzi F, et al. Efficacy of weight loss drugs on obesity and cardiovascular risk factors in obese adolescents: a meta-analysis of randomized controlled trials. Obes Rev 2010;11:150-8. 
31 Norgren $S$, Danielsson $P$, Jurold $R$, et al. Orlistat treatment in obese prepubertal children: a pilot study. Acta Paediatr. 2003;92:666-70.

32 Yanovski JA, Krakoff J, Salaita CG, et al. Effects of metformin on body weight and body composition in obese insulin-resistant children: a randomized clinical trial. Diabetes 2011;60:477-85.

33 Knowler WC, Barrett-Connor E, Fowler SE, et al. Reduction in the incidence of type 2 diabetes with lifestyle intervention or metformin. N Engl J Med 2002;346:393-403.

34 Christensen $\mathrm{R}$, Bartels EM, Astrup $A$, et al. Effect of weight reduction in obese patients diagnosed with knee osteoarthritis: a systematic review and meta-analysis. Ann Rheum Dis 2007;66:433-9.
35 Schnabel CA, Wintle M, Kolterman O. Metabolic effects of the incretin mimetic exenatide in the treatment of type 2 diabetes. Vasc Health Risk Manag 2006;2:69-77.

36 Ioannides-Demos LL, Piccenna L, McNeil JJ. Pharmacotherapies for obesity: past, current, and future therapies. J Obes 2011;2011:179674.

37 Black JA, White B, Viner RM, et al. Bariatric surgery for obese children and adolescents: a systematic review and meta-analysis. Obes Rev 2013;14:634-44.

38 Sachdev P, Makaya T, Marven SS, et al. Bariatric surgery in severely obese adolescents: a single-centre experience. Arch Dis Child 2014;99: 894-8. 